\title{
What Is the Best Pulmonary Diagnostic Approach for Wheezing Patients With Normal Spirometry?
}

\author{
William W Busse MD
}

\author{
Introduction \\ Does This Patient Have Asthma? \\ Does Reversibility of Air Flow Obstruction Exist in Asthma Even With \\ Normal Lung Functions? \\ Measurement of Airway Hyper-responsiveness \\ How Can AHR Be Measured? \\ What Have Been the Experiences in Detecting Asthma With Measures of \\ AHR? \\ What Is the Experience With Indirect, Hypertonic Solutions to Assess \\ AHR in Asthma? \\ What Other Indicators or Biomarkers Exist to Indicate Airway Inflammation \\ and May Assist in the Diagnosis of Asthma? \\ Summary
}

\begin{abstract}
Asthma is characterized by airway inflammation, airway hyper-responsiveness (AHR) and variable air flow obstruction. The diagnosis of asthma, however, is often based upon nonspecific clinical symptoms of cough, wheeze, and shortness of breath. Furthermore, the physical examination and measurements of pulmonary function are often unremarkable in patients with asthma, thereby complicating the diagnosis of the disease. The following discussion will review approaches to the diagnosis of asthma when lung functions are normal, and will largely focus on the use of bronchial provocation tests to detect underlying AHR. Key words: asthma; airway inflammation; airway hyperresponsiveness; bronchial provocation testing. [Respir Care 2012;57(1):39-46. (C) 2012 Daedalus Enterprises]
\end{abstract}

\section{Introduction}

Asthma is characterized by a number of features, which include bronchial hyper-responsiveness, airway inflamma-

\footnotetext{
Dr Busse is affiliated with the Division of Pulmonary and Critical Care Medicine, Department of Medicine, University of Wisconsin School of Medicine and Public Health, Madison, Wisconsin.

Dr Busse presented a version of this paper at the 48th RESPIRATORY CARE Journal Conference, "Pulmonary Function Testing," held March 25-27, 2011, in Tampa, Florida.

Dr Busse has disclosed relationships with Centocor, Merck, AstraZeneca, Boehringer Ingelheim, Novartis, TEVA, GlaxoSmithKline, Amgen,
}

tion, and variable air flow obstruction. ${ }^{1}$ These features are objective, can be quantitated, and form the basis for the diagnosis of asthma. The diagnosis of asthma, however, is often based upon clinical symptoms, which may include cough, wheezing, and shortness of breath. Unfortunately, these clinical manifestations are quite nonspecific and may reflect diseases other than asthma. For example, children with respiratory infections can have similar symptoms of

Pfizer, Medimmune, Genetech, Ception, the National Institute of Allergy and Infectious Diseases, and the National Heart, Lung, and Blood Institute.

DOI: $10.4187 /$ respcare.01449 
cough, wheeze, and shortness of breath, and this is not asthma. In adults, other respiratory diseases, including forms of chronic obstructive pulmonary disease (COPD), can also have these general clinical characteristics, or coexist with asthma. Although considerable heterogeneity can, and does, exist in asthma, the presence of airway hyper-responsiveness (AHR) and, in most patients, a reversible component to air flow obstruction should be a physiological component in the vast majority of patients with asthma. ${ }^{2}$ Therefore, when faced with a patient who is suspected of having asthma, it is helpful to have a rational approach to the diagnosis of asthma and from these data ascertain whether their "nonspecific" symptoms do indeed represent asthma. This is especially true when pulmonary functions are within "normal values," and, as a consequence, the diagnosis of asthma may not be readily apparent.

To set the stage for this discussion, it is helpful to frame this common clinical problem with the history of a patient in whom a diagnosis of asthma is suspected. The patient in this discussion is a 37-year-old woman with symptoms of cough, wheeze, and shortness of breath, which have been present intermittently over 6 months. As a child, she relates that she wheezed with colds, but she was not bothered by respiratory symptoms until 6 months ago. Over the past 3 weeks, in particular, her symptoms have escalated. She now awakens at night with coughing and experiences wheezing, at least weekly. Her exercise tolerance is also reduced such that she is unable to run without experiencing chest tightness. She also coughs when she laughs. Her physical examination is, however, normal. The question is, does this patient have asthma?

\section{Does This Patient Have Asthma?}

As discussed in the introduction, asthma is characterized by episodes of wheezing, cough, chest tightness, and shortness of breath. Although these symptoms are nonspecific and can be found in other diseases such as infectious bronchitis and COPD, they can also be intermittent in patients with asthma, thus accounting for a normal examination and measures of lung function. Prior to specific testing, the diagnosis of asthma can be strengthened by an identification of coexisting clinical manifestations. For example, a large portion of patients with asthma have allergic sensitization to environmental antigens. ${ }^{3}$ The association between allergic sensitization and asthma is particularly true in children. In addition, patients with asthma often have limitations to normal activity, including exercise. For many individuals, this inability to fully exercise is often ascribed to a lack of conditioning by the patient. To ascertain the presence of this clinical feature of asthma, it is often necessary to question patients in detail, because they frequently modify their lifestyle to prevent the appearance of symptoms or associated discomfort with activity. Finally, a very common and important feature of asthma is a presence of symptoms at night, particularly a cough. Again, patients often forget that their sleep had been interrupted because patterns of asthma frequently become ingrained, and accepted, as part of their lifestyle.

Two physiological features of asthma, reversible air flow obstruction and bronchial hyper-responsiveness, are not only key features of this disease but can also provide strong supportive evidence for the presence of asthma in patients with the described symptoms of cough, wheeze, and shortness of breath. ${ }^{4,5}$ Moreover, a demonstration of these features, particularly reversible air flow obstruction, helps make the diagnosis of asthma less ambiguous and assures both the patient and the clinician as to the presence of this underlying disease, a measure by which to monitor improvement and direction for treatment. Confirmation of a diagnosis of asthma is essential to achieve optimal disease control and important for the patient's overall well-being, as current treatments are highly effective and safe. ${ }^{6}$

In returning to our patient, pulmonary functions were measured. She had an $\mathrm{FEV}_{1}$ of $2.7 \mathrm{~L}(3.0 \mathrm{~L}$ was the predicted value). The $\mathrm{FEV}_{1}$ was $90 \%$ predicted normal value. Her FVC was $3.1 \mathrm{~L}$, with a predicted value of $3.75 \mathrm{~L}$, and the $\mathrm{FEV}_{1} / \mathrm{FVC}$ was $87 \%$. All of these values fall within the normal range for her age, height, and sex. The presence of normal pulmonary functions, however, is not unusual even when asthma exists. Unless a patient with asthma is seen during a period of symptoms or they have persistent, poorly controlled severe disease, this scenario is not unusual but can leave the clinician in a quandary as to whether asthma exists in this specific patient. Given this common occurrence, it is helpful to consider what approaches can be used to confirm that asthma exists and that underlying asthma may be responsible for symptoms when baseline lung functions are normal.

\section{Does Reversibility of Air Flow Obstruction Exist in Asthma Even With Normal Lung Functions?}

The American Thoracic Society has defined reversible airway disease as showing an improvement in $\mathrm{FEV}_{1}$ of $12 \%$ with a minimum volume improvement of $200 \mathrm{~mL}$. $^{7}$ For patients with reduced baseline lung functions, this degree of improvement in the $\mathrm{FEV}_{1}$ is often seen. Greater improvements in $\mathrm{FEV}_{1}$ values are more often to be found in patients with a greater degree of air flow obstruction. ${ }^{8}$ In fact, in many clinical trials where the mean $\mathrm{FEV}_{1}$ is less than $80 \%$, predicted $\mathrm{FEV}_{1}$ improvement is frequently greater than $12 \%$ and frequently achieves improvement well over $20 \% .^{8}$

Many patients with underlying asthma have normal lung functions, and this relationship is recognized in asthma guidelines. Asthma guidelines define mild persistent asthma 
with lung function $\geq 80 \%$ predicted. ${ }^{6}$ In children, the presence of normal lung functions is especially frequent despite active, symptomatic asthma. In the Childhood Asthma Management Program (CAMP), lung functions on entry to the study in the recruited patients were "normal" (ie, $\mathrm{FEV}_{1}>80 \%$ predicted), but yet many had improvement in these "normal" values following the administration of an inhaled $\beta_{2}$ agonist.9

Similar characteristics are seen in adult patients with asthma. In 2001, the National Heart, Lung, and Blood Institute established a program to define severe asthma: Severe Asthma Research Program (SARP). ${ }^{10}$ As part of the SARP program, nearly 1,000 patients with asthma have been recruited and carefully evaluated to identify a large spectrum of phenotypic features. ${ }^{2}$ To describe and define asthma characteristics of subjects recruited into SARP, a cluster analysis was performed. In this unbiased analysis, 5 distinct patient clusters emerged. Although overlap exists among these 5 clusters, the severity of asthma ranged from mild to severe, with each cluster having distinct clinical and physiological features. ${ }^{2}$

Patients who were segregated into Cluster 1 were considered, by the investigators, to have mild asthma. They had few symptoms, a limited need for and use of controller medication, and infrequent exacerbations. All had a clinical diagnosis of asthma, which had been confirmed by a SARP investigator. The mean $\mathrm{FEV}_{1}$ per predicted, at enrollment in Cluster 1 patients, was $102 \%$, and the $\mathrm{FEV}_{1} /$ FVC was 0.78 . To determine whether there was "reversibility," the recruited patients were given up to 8 inhalations of albuterol (90 $\mu \mathrm{g} / \mathrm{inh}$ alation). In the Cluster 1 cohort, the $\mathrm{FEV}_{1}$ percent of predicted values increased from mean value of $102 \%$ predicted to a mean value of $113 \%$ predicted. Therefore, even in the face of baseline normal pulmonary function, reversibility of air flow obstruction can be demonstrated in about one half of the patients. This information is helpful to assist and support the diagnosis of asthma.

\section{Measurement of Airway Hyper-responsiveness}

Another characteristic feature of asthma is AHR, which is marked by an enhanced contractual airway response to substances that either cause the release of mediators to provoke bronchospasm, for example, mannitol, or act directly to contract airway smooth muscle, for example, methacholine. ${ }^{4,5}$ AHR in asthma is complex and composed of a variety of factors.

Factors that govern AHR have been, arbitrarily, divided into 2 major components: persistent and variable (Fig. 1). Features included under "persistent" components have been ascribed to structural changes such as airway smooth muscle hypertrophy or an alteration in the architecture of the bronchial wall, such as an increased thickness of the mu-

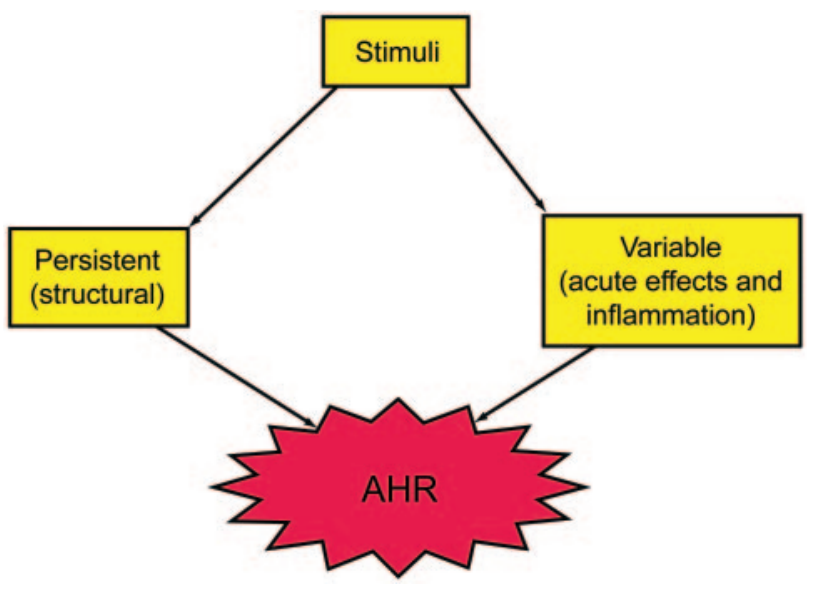

Fig. 1. Components of airway changes that contribute to airway hyper-responsiveness (AHR). (From Reference 4, with permission.)

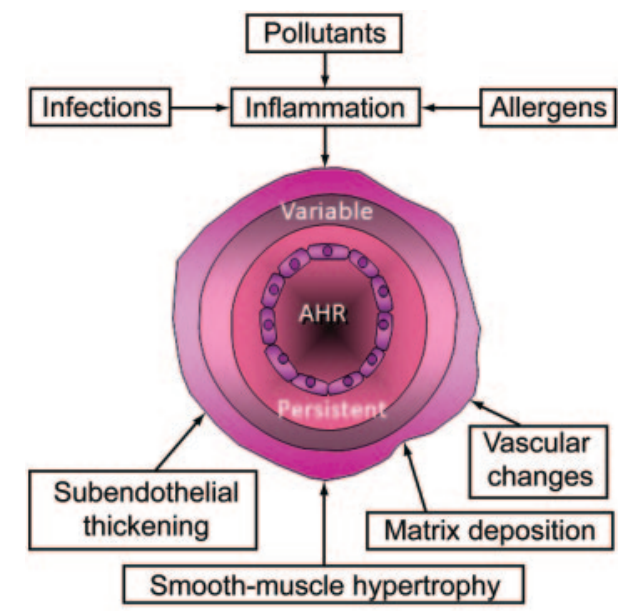

Fig. 2. Factors affecting the variable and persistent components of airway hyper-responsiveness (AHR). (From Reference 4, with permission.)

cosal layer. These structural changes are proposed to enhance the sensitivity of the airway to a contractual response when challenged by methacholine, for example. In addition, it has been proposed that a variable component of the airway exists that contributes to AHR in asthma: inflammation. Although a separation into these two components is helpful for discussion, there is, in all probability, a considerable overlap between these two contributing factors and synergistic actions.

AHR is substantially influenced by respiratory infections, allergen exposures, and pollutants, which act to increase bronchial sensitivity. The increase in AHR to these stimuli is likely the result of the generation of inflammation (Fig. 2). The accentuation in underlying AHR that occurs in response to these inflammatory reactions is frequently transient (ie, weeks to months), but returns to the baseline levels either spontaneously or as a consequence 


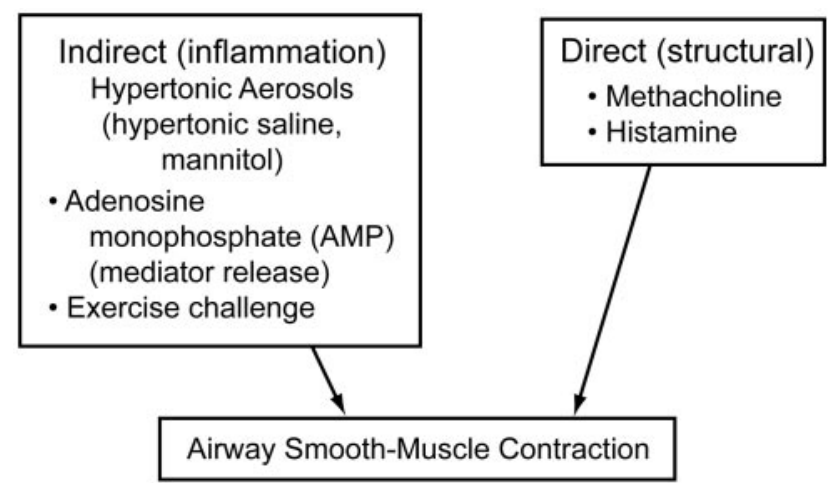

Fig. 3. Agents that can be used to detect airway hyper-responsiveness (AHR) and classification as to effects of direct versus indirect. (From Reference 4, with permission.)

of treatment. In some situations, however, when the exposure is great, or prolonged, this increase in AHR can become more persistent or even permanent as the result of further injury to the airway.

\section{How Can AHR Be Measured?}

In considering the concept of 2 components of airway contributing to AHR, structural and variable, 2 classes of "activators" have been identified and used to measure this feature of asthma (Fig. 3). Methacholine and histamine are contractile substances that act directly on airway smooth muscle to elicit contraction. Because of the structural alterations in the airway that may occur in asthma, the sensitivity to and resulting contraction that arises following an inhalation of methacholine or histamine is greater (Fig. 4). ${ }^{11}$ There are 2 distinct responses that occur in asthma in the response to either methacholine or histamine when compared to events in normal subjects. First, the relative contraction, as reflected in the fall in $\mathrm{FEV}_{1}$, occurs at a lower concentration of agonist, which reflects an increased sensitivity of the airway. Second, in patients with more severe disease, in particular, the overall contractile response is greater and, in contrast to that seen in normal subjects or patients with mild disease, there is not a plateauing of the contractile response. The usual "cutoff" dose for a positive $\mathrm{PC}_{20}$ (provocation concentration causing a $20 \%$ fall in $\mathrm{FEV}_{1}$ ) of methacholine in asthma is $8 \mathrm{mg} / \mathrm{mL} .{ }^{5}$ However, in patients with more severe disease, the concentrations of methacholine necessary to elicit these responses are less (ie, $\leq 2 \mathrm{mg} / \mathrm{mL}$ ).

There are a number of "indirect" acting substances that are available for use to detect AHR in asthma, for example, hypertonic saline, mannitol, and adenosine monophosphate (AMP). Mannitol and hypertonic saline generate airway contraction as the result of an increase in airway osmolarity, which then causes mast cell mediator release

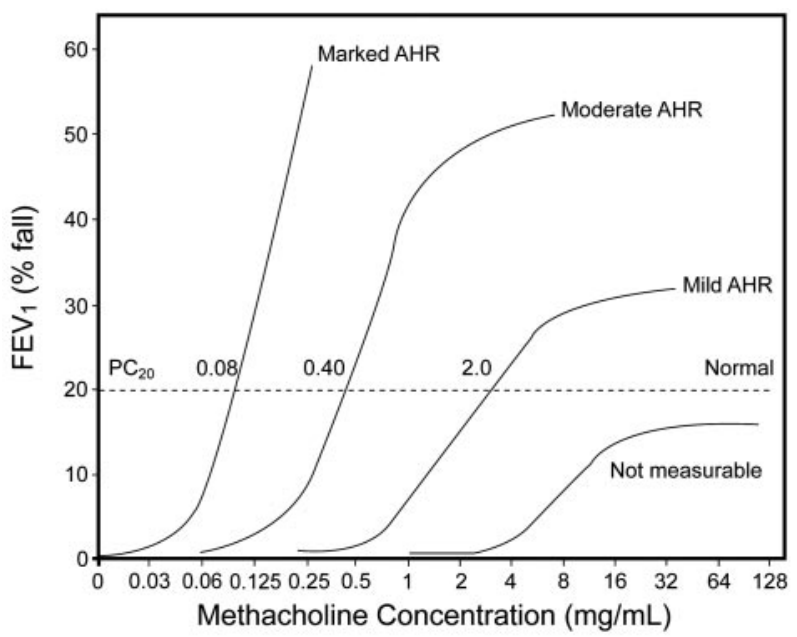

Fig. 4. Hypothetical methacholine dose-response curves for four individuals: one with normal airway responsiveness, and one each with mild, moderate, and marked airway hyper-responsiveness (AHR). These four curves demonstrate hyper-responsiveness both in the increase in magnitude of the response and the ease of the response, the latter identified by the leftward shift of the curve and the smaller $\mathrm{PC}_{20}$ (provocation concentration causing a $20 \%$ fall in $\mathrm{FEV}_{1}$ ). The $\mathrm{PC}_{20}$ values decrease from non-measurable in the normal curve to $2.0 \mathrm{mg} / \mathrm{mL}$ in a subject with mild AHR, $0.40 \mathrm{mg} / \mathrm{mL}$ in a subject with moderate AHR, and $0.08 \mathrm{mg} / \mathrm{mL}$ in a subject with marked AHR. One important caveat is that mild, moderate, and marked AHR do not equate with mild, moderate, and severe asthma or necessarily with differences in asthma severity and the degree of asthma control. (From Reference 11, with permission.)

of airway contractile substances. AMP, in contrast, acts directly on the mast cell to stimulate release of its mediators. In addition, other approaches can be used to identify the presence of AHR, including exercise or eucapnic hyperventilation. The principal effects of these 2 stimuli to provoke AHR are also the result of increased airway osmolarity.

\section{What Have Been the Experiences in Detecting Asthma With Measures of AHR?}

The greatest amount of experience in measuring AHR has been with the use of methacholine administered using compressor-driven nebulizers. As depicted in Figure 4, there can be considerable variability in the level of AHR in asthma. In patients with more severe disease, $\mathrm{PC}_{20}$ values are usually low (ie, $\leq 1$ to $4 \mathrm{mg} / \mathrm{mL}$ ) and reflect high levels of AHR.

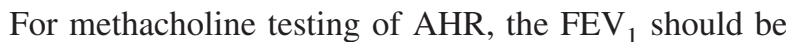
$\geq 70 \% .{ }^{12}$ This requirement has been suggested for safety reasons to prevent excessive reactions in patients who already have compromised pulmonary function, and may result in obstructive responses that are profound. However, under carefully monitored situations, experience with methacholine products has been safe even when $\mathrm{FEV}_{1}$ 


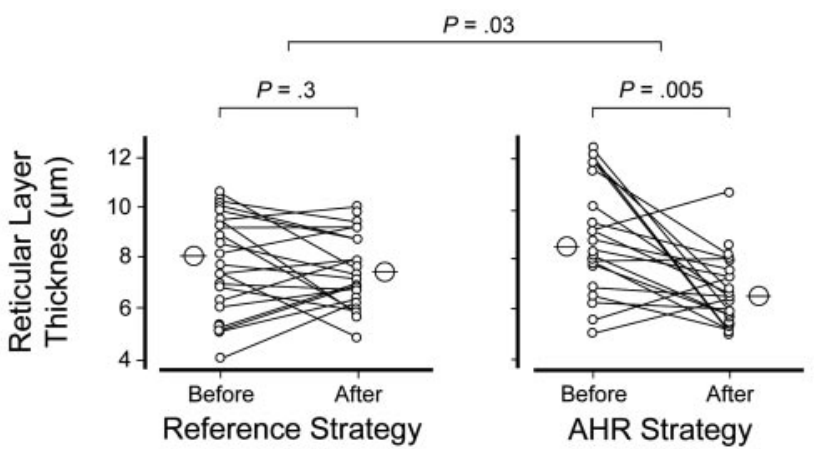

Fig. 5. The effect of treatment with inhaled corticosteroids directed toward modifying airway hyper-responsiveness (AHR strategy) and standard care (reference strategy) on the thickness of the reticular basement member. (From Reference 13, with permission.)

values are less than $60 \%$. This, however, cannot be recommended for general use at present. Methacholine is commercially available as Provocholine.

Treatment used in asthma can also have an important effect on AHR in patients and on these observations. In a study by Sont and colleagues, ${ }^{13}$ the investigators designed a trial to evaluate the effect on asthma control when doses of inhaled corticosteroids (ICS) were given to reduce AHR. To accomplish this effect of AHR, the investigators needed to use higher doses of ICS. There were a number of effects on asthma measures when AHR was reduced by this approach. Lung functions improved, asthma symptoms were less, exacerbations were fewer, and histological changes were also noted in bronchial biopsies (Fig. 5). In particular, the thickness of the subbasement layer of the bronchial membrane was reduced. Whether this change in the structure of the airway contributed to the improvement in AHR was not fully established, but this possibility fits well with the concepts discussed.

\section{What Is the Experience With Indirect, Hypertonic Solutions to Assess AHR in Asthma?}

Mannitol is now available as capsules of dry powder, under the trade name of Aridol, and provides the community with another FDA-approved product for measures of AHR. Anderson and Brannan ${ }^{14}$ have described their experience with mannitol to assess and define AHR in asthma. First, 2 end points are considered to indicate heightened AHR as exists in asthma: a $15 \%$ fall in $\mathrm{FEV}_{1}$ at a cumulative dose of mannitol of $635 \mathrm{mg}$, or less. In performing this test, dosing is begun at $0.5 \mathrm{mg}$ of mannitol and gradually increased to the highest dose of $160 \mathrm{mg}$ (dosing schedule: $0.5,10,20,40,80,160,160,160$, and $160 \mathrm{mg}$ ) with $\mathrm{FEV}_{1}$ measurements made 60 seconds after delivering a dose. A second end point that reflects AHR to mannitol is a $10 \%$ fall in $\mathrm{FEV}_{1}$ between consecutive doses.

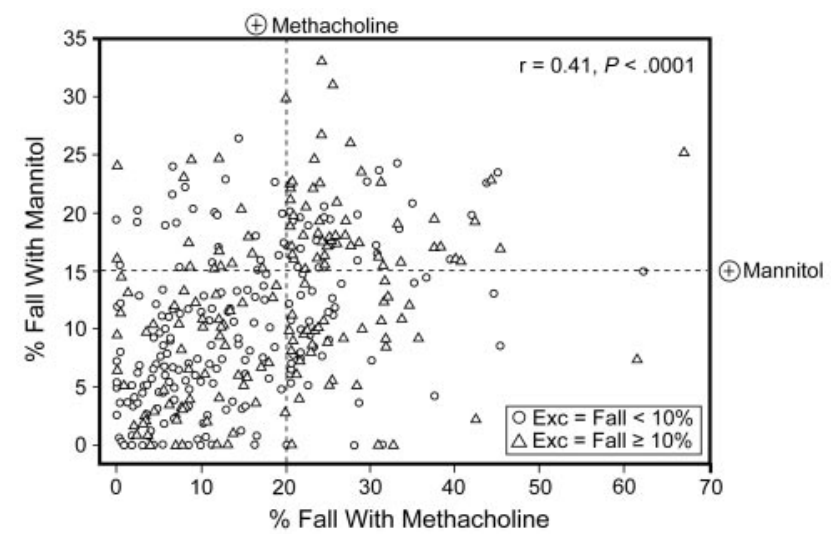

Fig. 6. The maximum percentage fall in $\mathrm{FEV}_{1}$ for mannitol and methacholine in subjects in the per-protocol populations. Exc = exercise. (From Reference 15, with permission.) (Courtesy of BioMed Central)

Anderson and colleagues ${ }^{15}$ have also recently reported on a study in which the investigators compared mannitol and methacholine to predict exercise-induced bronchospasm and eventual clinical diagnosis of asthma. Threehundred seventy-five subjects were recruited, and, at the time of recruitment, it was unknown to the investigators whether the patient had asthma. Each subject underwent 2 standard exercise challenges, along with a methacholine and mannitol provocative test. The recruited subjects were also evaluated by a physician for the diagnosis of asthma, which was based on history, a response to a bronchodilator, skin testing for allergic sensitization, and the results of the 2 exercise tests.

As noted in Figure 6, the maximum fall in $\mathrm{FEV}_{1}$ to mannitol and methacholine was variable among the recruited subjects and variable between the 2 testing agents. Although there was a significant correlation and overlap between these 2 provocative testing approaches, there was variability in the responses of individual patients between mannitol and methacholine and exercise-induced bronchospasm. This variability in response suggests that individuals may have a positive response to mannitol and not methacholine, and vice versa, likely reflecting the predominant cause of the underlying AHR. These experiences raise a number of questions. Should patients undergo provocations with both direct and indirect stimuli? The availability of 2 different stimuli gives the clinician or investigator another line of approach should one test be negative but a high level of suspicion for asthma remains.

Attempts have been made to compare the causes that may explain variabilities in responses between these 2 agents (Table 1). What these assessments suggest is that the response to methacholine, for example, reflects changes in airway structure and caliber. These cumulative findings also suggest that the response to methacholine has high sensitivity, but low specificity. That is, a negative response 
Table 1. Comparison of Direct and Indirect Challenges ${ }^{4}$

\begin{tabular}{lcc}
\hline \hline \multicolumn{1}{c}{ Measure } & $\begin{array}{c}\text { Direct } \\
\text { (Methacholine) }\end{array}$ & $\begin{array}{c}\text { Indirect } \\
\text { (Mannitol) }\end{array}$ \\
\hline Muscle function & ++++ & ++ \\
Airway caliber & ++++ & \pm \\
Inflammation & ++ & ++++ \\
Dose needed & Low & High \\
Dose limitation & No & Yes \\
Sensitivity & High & Low \\
Specificity & Fair & High \\
Diagnostic & Rule out & Rule in, assess for EIB \\
& & \\
\hline$+=$ strength of the relationship (greater number of + indicates greater strength) \\
$\pm=$ uncertain but probably no relation & \\
EIB = exercise-induced bronchospasm. & \\
\hline
\end{tabular}

to methacholine largely rules out asthma. However, a positive response to methacholine, while compatible with asthma, may not be specific for asthma and can occur in other conditions as well. In contrast, and according to Cockcroft, ${ }^{16}$ positive responses to indirect challenges largely reflect underlying, existing inflammation and have low sensitivity but high specificity. Having available both approaches will allow for a greater overall ability to detect and establish the existence of AHR, and, hence, the likely existence of asthma.

\section{What Other Indicators or Biomarkers Exist to Indicate Airway Inflammation and May Assist in the Diagnosis of Asthma?}

Airway inflammation can be assessed through a number of safe, noninvasive methods, including sputum analysis for cell counts, particularly the presence of eosinophils, and measures of exhaled nitric oxide (FeNO). Nitric oxide is generated by epithelial cells and is increased in the presence of airway inflammation. ${ }^{17}$ A number of studies have used exhaled nitric oxide to detect underlying airway inflammation. The test is noninvasive, reproducible, and standardized. However, the use of FeNO in clinical and diagnostic settings has yet to be fully established, nor has the importance of elevated FeNO to asthma been fully agreed upon. ${ }^{18-20}$

To illustrate, Smith and colleagues ${ }^{21}$ reported on the use of a variety of tests, including FeNO, to diagnosis asthma. They recruited 47 consecutively seen patients, who ranged in age from 8 to 75 years. The recruited subjects were being evaluated for asthma. At the time of recruitment, the patients had no respiratory symptoms for the preceding 6 weeks; the investigative approach for the study is described in Table 2. In Table 3, the features of patients with asthma, and those without asthma, are presented. As expected,
Table 2. Study Plan

\begin{tabular}{|c|c|c|c|c|c|}
\hline & \multicolumn{2}{|c|}{ Visit 1} & \multicolumn{2}{|c|}{ Visit 2} & \multirow[b]{2}{*}{ Visit 3} \\
\hline & Initial & 2 week & Initial & 2 week & \\
\hline Clinical asthma assessment & $\mathrm{X}$ & & & & \\
\hline FeNO measurement & $\mathrm{X}$ & & $X$ & & X \\
\hline Skin allergy test & $\mathrm{X}$ & & & & \\
\hline Spirometry & $\mathrm{X}$ & & $\mathrm{X}$ & & $\mathrm{X}$ \\
\hline Bronchodilator reversibility & $\mathrm{X}$ & & & & \\
\hline Hypertonic saline challenge & & & $\mathrm{X}$ & & $\mathrm{X}$ \\
\hline Sputum induction & & & $\mathrm{X}$ & & \\
\hline Peak flow measurements & & $\mathrm{X}$ & & $\mathrm{X}$ & \\
\hline Trial of oral prednisone & & & & $\mathrm{X}$ & \\
\hline
\end{tabular}

FeNO $=$ fraction of exhaled nitric oxide

patients with asthma had lower lung function, a greater bronchodilation response, and higher FeNO values and sputum eosinophils. Smith et $\mathrm{al}^{21}$ went on to evaluate their data for sensitivity and specificity, as well as the positive and negative values for each of the diagnostic tests (Table 4).

Based on the results of their study, Smith et al ${ }^{21}$ found high levels of specificity for asthma based on the result of the pulmonary function tests. Similarly, FeNO and sputum eosinophils were highly sensitive and specific as predictive indices for asthma. The overall experience with FeNO, however, remains limited, and its use, in clinical asthma, has yet to be fully established and integrated into both diagnosis and treatment of asthma. ${ }^{18-20}$ As an indicator of airway inflammation, FeNO is sensitive. However, if the patient has been using inhaled corticosteroids, the levels of FeNO in exhaled breath become a less precise index for the presence of asthma. This relationship has been seen in patients in the SARP program..$^{2}$ In the Cluster 1 group, exhaled nitric oxide was modestly elevated, but asthma existed in these patients. The reduced FeNO levels, overall, likely reflect the fact that many of these individuals had already received ICS for asthma treatment.

Another marker of inflammation in asthma has been the presence of sputum eosinophils. Sputum eosinophils are usually found in patients who have an allergic component to their disease, but elevated sputum eosinophils may also reflect patients who are resistant to ICS. ${ }^{22,23} \mathrm{O}^{\prime}$ Byrne and colleagues $^{24}$ compared sputum eosinophils to airway responsiveness to either mannitol or methacholine (Figs. 7 and 8). Significant correlations were found between sputum eosinophils and airway responsiveness to mannitol, but not with methacholine. These data suggest that the hyper-responsive response to mannitol may relate to inflammation rather than to structural changes in the airway architecture. 
Table 3. Characteristics of the Study Participants by Asthma Diagnosis ${ }^{5 *}$

\begin{tabular}{|c|c|c|}
\hline & $\begin{array}{l}\text { Patients With Asthma } \\
\quad(\text { no. }=17)\end{array}$ & $\begin{array}{l}\text { Subjects Without Asthma } \\
(\text { no. }=30)\end{array}$ \\
\hline Age, mean (range), y & 41.6 (range 9-72) & 31.8 (range 9-64) \\
\hline Smoking history (mean pack-years) & $\begin{array}{c}14 \text { nonsmokers } \\
3 \text { ex-smokers: } 11.3\end{array}$ & $\begin{array}{c}28 \text { nonsmokers } \\
2 \text { ex-smokers: } 12.5\end{array}$ \\
\hline Sex & $\begin{array}{c}8 \text { female }(47 \%) \\
9 \text { male }\end{array}$ & $\begin{array}{c}19 \text { female }(63 \%) \\
11 \text { male }\end{array}$ \\
\hline $\mathrm{FEV}_{1}(\mathrm{~L})$ & $2.71 \pm 1.16$ & $3.18(0.82)$ \\
\hline $\mathrm{FEV}_{1}(\%$ predicted $)$ & $90.5 \pm 18.4$ & $110.0(13.5) \dagger$ \\
\hline $\mathrm{FEV}_{1} / \mathrm{FVC}$ ratio $(\%)$ & $77.3 \pm 11.9$ & $84.9(6.0) \ddagger$ \\
\hline Bronchodilator reversibility (\%) & $11.6 \pm 9.6$ & $4.2(2.5) \dagger$ \\
\hline Peak flow variation $(\%)$ & $8.3 \pm 5.4$ & $5.5(2.5)$ \\
\hline FeNO (ppb) $(50 \mathrm{~mL} / \mathrm{s})$ & $52.0 \pm 34.0$ & $15.7(12.9) \S$ \\
\hline Sputum eosinophils (\%) & $13.8 \pm 10.0$ & $1.8(5.0) \S$ \\
\hline Sputum neutrophils (\%) & $20.5 \pm 16.7$ & $35.5(21.6) \div$ \\
\hline \multicolumn{3}{|c|}{$\begin{array}{l}\text { * All values are reported as mean } \pm \mathrm{SD} \text { unless otherwise stated. Bronchodilator reversibility is the percent increase in } \mathrm{FEV}_{1} 15 \text { min after inhalation of albuterol. Peak flow variability is expressed as } \\
\text { the amplitude percent mean calculated over } 7 \text { days. } \\
\dagger P<.001 \text { for between-group comparisons. } \\
\vdots P<.05 \text { for between-group comparisons. } \\
\S P<.001 \text { for between-group comparisons. }\end{array}$} \\
\hline
\end{tabular}

Table 4. Sensitivity, Specificity, and Positive and Negative Predictive Values for Each of the Diagnostic Tests for Asthma ${ }^{5 *}$

\begin{tabular}{|c|c|c|c|c|c|c|c|c|}
\hline & \multicolumn{2}{|c|}{$\begin{array}{l}\text { Asthma } \\
(n=17)\end{array}$} & \multicolumn{2}{|c|}{$\begin{array}{l}\text { Nonasthma } \\
(n=30)\end{array}$} & \multirow{2}{*}{$\begin{array}{c}\text { Sensitivity } \\
(\%)\end{array}$} & \multirow{2}{*}{$\begin{array}{l}\text { Specificity } \\
(\%)\end{array}$} & \multirow{2}{*}{$\begin{array}{l}\text { Positive } \\
\text { Predictive } \\
\text { Value }(\%)\end{array}$} & \multirow{2}{*}{$\begin{array}{l}\text { Negative } \\
\text { Predictive } \\
\text { Value }(\%)\end{array}$} \\
\hline & Yes & No & Yes & No & & & & \\
\hline Bronchodilator reversibility $>12 \%$ & 7 & 10 & 0 & 30 & ND & ND & ND & ND \\
\hline Bronchial hyperresponsiveness $<20 \mathrm{~mL}$ & 15 & 2 & 0 & 30 & ND & ND & ND & ND \\
\hline Peak flow variation $>20 \%$ & 0 & 17 & 0 & $29 \dagger$ & 0 & 100 & NA & 70 \\
\hline Peak flow improvement with steroid $>15 \%$ & 4 & 13 & 0 & $29 \dagger$ & 24 & 100 & 100 & 69 \\
\hline $\mathrm{FEV}_{1}<80 \%$ predicted & 5 & 12 & 0 & 30 & 29 & 100 & 100 & 71 \\
\hline $\mathrm{FEV}_{1}<90 \%$ predicted & 6 & 11 & 2 & 28 & 35 & 93 & 75 & 72 \\
\hline $\mathrm{FEV}_{1} / \mathrm{FVC}<70 \%$ & 6 & 11 & 0 & 30 & 35 & 100 & 100 & 73 \\
\hline $\mathrm{FEV}_{1} / \mathrm{FVC}<80 \%$ & 8 & 9 & 6 & 24 & 47 & 80 & 57 & 73 \\
\hline $\mathrm{FEV}_{1}$ improvement with steroid $>15 \%$ & 2 & 15 & 0 & $29 \dagger$ & 12 & 100 & 100 & 66 \\
\hline Sputum eosinophils $>3 \%$ & 12 & $2 \dagger$ & 3 & $23 \dagger$ & 86 & 88 & 80 & 92 \\
\hline FeNO $(50 \mathrm{~mL} / \mathrm{s})>20 \mathrm{ppb}$ & 14 & $2 \ddagger$ & 6 & $22 \ddagger$ & 88 & 79 & 70 & 92 \\
\hline $\begin{array}{l}\text { * Data for bronchodilator reversibility and bronchial hyperre } \\
\dagger \text { Patient unable or unwilling to complete procedure. } \\
\text { ‡ Technical difficulties prevented completion of exhaled nitr } \\
\text { ND = no data (not calculated) } \\
\text { NA = not applicable }\end{array}$ & $\begin{array}{l}\text { iveness } \\
\text { ide (FeN }\end{array}$ & $\begin{array}{l}\text { pertoni } \\
\text { easure }\end{array}$ & $\begin{array}{l}\text { ne are } \mathrm{n} \\
\text { at } 50 \mathrm{n}\end{array}$ & en bec: & oth these parame & vere used to diag & asthma. & \\
\hline
\end{tabular}

\section{Summary}

Patients with asthma can have normal lung function even though they have active and symptomatic disease. A number of diagnostic approaches can be used to determine the presence of features of asthma that support the diagnosis of this disease. Of considerable interest have been methods to detect and define underlying AHR. AHR is influenced by a number of factors, including altered airway structure and inflammation. The use of methacholine and hypertonic solutions has been informative in eliciting the presence and severity of AHR. These 2 agents appear to detect predominantly different components of airway abnormalities in asthma: methacholine-structural changes and mannitol-inflammation. The application of these tests provides the clinician with effective tools to detect AHR. In patients with asthma-like symptoms, the results of inhalation challenge tests, direct or indirect, modify the pretest probability of asthma, but do not make the diagnosis of asthma. 


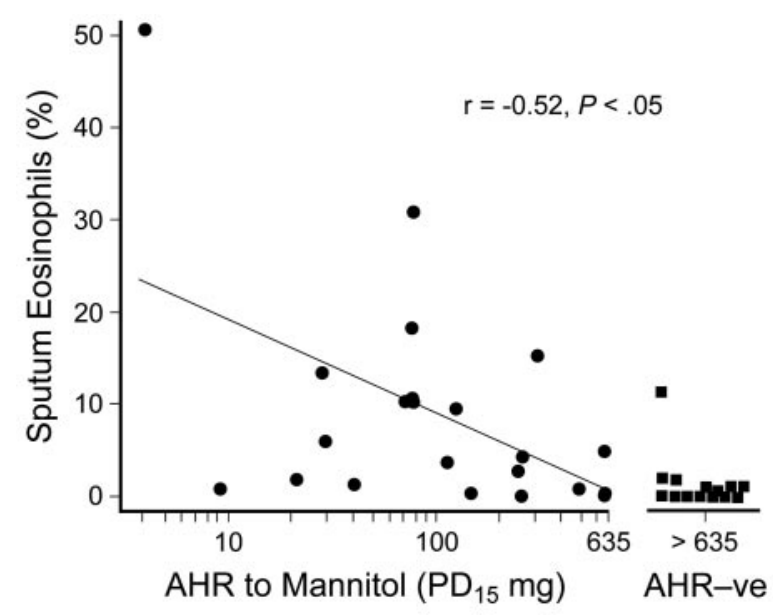

Fig. 7. A comparison between airway hyper-responsiveness (AHR) to mannitol and percentage of sputum eosinophils. $\mathrm{PD}_{15}=$ provocational dose that caused $a \geq 15 \%$ decrease in FEV 1 . (From Reference 24 , with permission.)

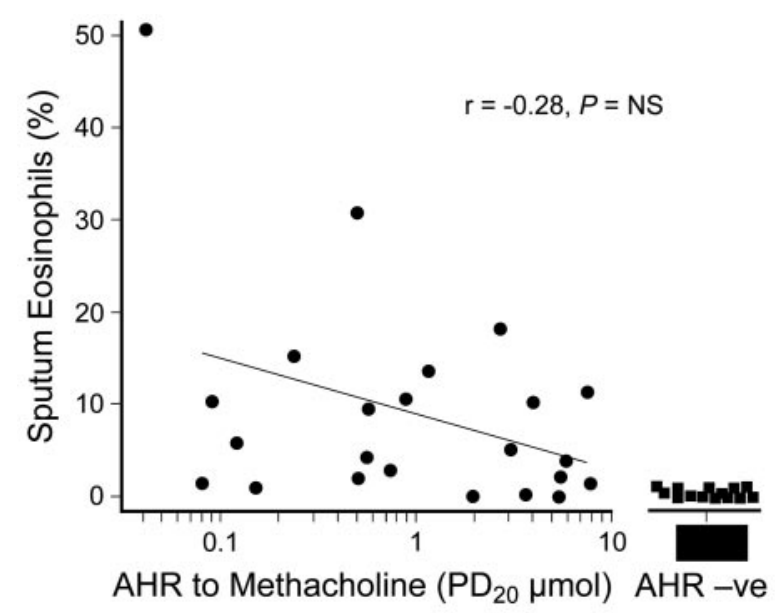

Fig. 8. A comparison of airway hyper-responsiveness (AHR) to methacholine and percentage of sputum eosinophils. The black box represents patients with no evidence of airway hyper-responsiveness (AHR-ve). (From Reference 24, with permission.)

\section{REFERENCES}

1. Busse WW, Lemanske RF Jr. Asthma. N Engl J Med 2001;344(5): 350-362.

2. Moore WC, Meyers DA, Wenzel SE, Teague WG, Li H, Li X, et al. Identification of asthma phenotypes using cluster analysis in the Severe Asthma Research Program. Am J Respir Crit Care Med 2010; 181(4):315-23.

3. Platts-Mills T, Vaughan J, Squillace S, Woodfolk J, Sporik R. Sensitisation, asthma, and a modified $\mathrm{Th} 2$ response in children exposed to cat allergen: a population-based cross-sectional study. Lancet 2001; 357(9258):752-756.

4. Busse WW. The relationship of airway hyperresponsiveness and airway inflammation: airway hyperresponsiveness in asthma: its measurement and clinical significance. Chest 2010;138(2 Suppl):4S-10S.

5. Cockcroft DW, Davis BE. Mechanisms of airway hyperresponsiveness. J Allergy Clin Immunol 2006;118(3):551-559.
6. National Heart Lung and Blood Institute. Expert Panel Report 3 (EPR-3): guidelines for the diagnosis and management of asthma full report 2007. www.nhlbi.nih.gov/guidelines/asthma/asthgdln.htm. Accessed October 31, 2011.

7. Boushey HA. Clinical diagnosis in adults. In: Barnes PJ, Grunstein MJ, Leff AR, Woolcock AJ, editors. Asthma. Baltimore: LippincottRaven; 1997;1391-1403.

8. Bateman ED, Boushey HA, Bousquet J, Busse WW, Clark TJ, Pauwels RA, et al. Can guideline-defined asthma control be achieved? The Gaining Optimal Asthma ControL study. Am J Respir Crit Care Med 2004;170(8):836-844.

9. Long-term effects of budesonide or nedocromil in children with asthma. The Childhood Asthma Management Program Research Group. N Engl J Med 2000;343(15):1054-1063.

10. Wenzel SE, Busse WW. Severe asthma: lessons from the Severe Asthma Research Program. J Allergy Clin Immunol 2007;119(1):14-21.

11. Cockcroft DW. Bronchial challenge testing. In: Adkinson NF Jr, Bochner BS, Busse WW, Holgate ST, Lemanske RF Jr, Simons FER, editors. Middleton's Allergy Principles \& Practice. London: Elsevier; 2009:1295-1308.

12. American Association for Respiratory Care. Clinical Practice Guideline. Methacholine challenge testing: 2001 revision \& update. Respir Care 2001;46(5):523-530.

13. Sont JK, Willems LN, Bel EH, Van Krieken JH, Vandenbroucke JP, Sterk PJ. Clinical control and histopathologic outcome of asthma when using airway hyperresponsiveness as an additional guide to long-term treatment. The AMPUL Study Group. Am J Respir Crit Care Med 1999;159(4 Pt 1):1043-1051.

14. Anderson SD, Brannan JD. Bronchial provocation testing: the future. Curr Opin Allergy Clin Immunol 2011;11(1):46-52.

15. Anderson SD, Charlton B, Weiler JM, Nichols S, Spector SL, Pearlman DS; A305 Study Group. Comparison of mannitol and methacholine to predict exercise-induced bronchoconstriction and a clinical diagnosis of asthma. Respir Res 2009;10:4.

16. Cockcroft DW. Direct challenge tests: airway hyperresponsiveness in asthma: its measurement and clinical significance. Chest 2010; 138(2 Suppl):18S-24S.

17. Barnes PJ, Dweik RA, Gelb AF, Gibson PG, George SC, Grasemann $\mathrm{H}$, et al. Exhaled nitric oxide in pulmonary diseases: a comprehensive review. Chest 2010;138(3):682-692.

18. Malmberg LP, Pelkonen AS, Haahtela T, Turpeinen M. Exhaled nitric oxide rather than lung function distinguishes preschool children with probable asthma. Thorax 2003;58(6):494-499.

19. Deykin A, Massaro AF, Drazen JM, Israel E. Exhaled nitric oxide as a diagnostic test for asthma: online versus offline techniques and effect of flow rate. Am J Respir Crit Care Med 2002;165(12):1597-1601.

20. Jatakanon A, Lim S, Kharitonov SA, Chung KF, Barnes PJ. Correlation between exhaled nitric oxide, sputum eosinophils, and methacholine responsiveness in patients with mild asthma. Thorax 1998; 53(2):91-95.

21. Smith AD, Cowan JO, Filsell S, McLachlan C, Monti-Sheehan G, Jackson P, et al. Diagnosing asthma: comparisons between exhaled nitric oxide measurements and conventional tests. Am J Respir Crit Care Med 2004;169(4):473-478.

22. Nair P, Pizzichini MM, Kjarsgaard M, Inman MD, Efthimiadis A, Pizzichini E, et al. Mepolizumab for prednisone-dependent asthma with sputum eosinophilia. N Engl J Med 2009;360(10):985-993.

23. Haldar P, Brightling CE, Hargadon B, Gupta S, Monteiro W, Sousa A, et al. Mepolizumab and exacerbations of refractory eosinophilic asthma. N Engl J Med 2009;360(10):973-984.

24. O'Byrne PM, Gauvreau GM, Brannan JD. Provoked models of asthma: what have we learnt? Clin Exp Allergy 2009;39(2):181-192. 


\section{Discussion}

Kaminsky: I have a question regarding the mannitol test, to try to diagnose AHR. Since it's considered an indirect test and therefore should theoretically "incite inflammation to some degree" by activating mast cells or some other effect, does anybody know or have any data on the safety of it as far as reversibility? The one nice thing about methacholine is, no matter how tight people get, I've never seen someone not reverse with albuterol.

Busse: I think in the literature ${ }^{1}$ they looked at reversibility time after a positive test, and they were very similar.

1. Leuppi JD, Tandjung R, Anderson SD, Stolz $\mathrm{D}$, Brutsche MH, Bingisser R, et al. Predition of treatment-response to inhaled corticosteroids by mannitol-challenge test in COPD. A proof of concept. Pulm Pharmacol Ther 2005;18(2):83-88.

Rundell:* Incidentally, I was one of the high-end rollers in the Aridol 305 phase III clinical trial ${ }^{1}$ that Dr Busse just presented, and I'd like to make a couple comments on that after I address your issue, but, simply stated, these studies and others that have been done have shown no difference between methacholine and mannitol in terms of reversibility after a positive test, sensitivity and specificity to clinical diagnosis, or to exercise or EVH [eucapnic voluntary hyperventilation]. Late phase response to mannitol has not been different either.

1. Pearlman D. A phase III multicenter study to demonstrate the sensitivity and specificity of Aridol (mannitol) challenge to predict bronchial hyper-responsiveness as manifested by a positive exercise challenge in subjects presenting with signs and symptoms suggestive of asthma but without a definitive diagnosis. http://clinicaltrials. gov/ct2/show/NCT00252291. Accessed September 26, 2011.

\footnotetext{
* Kenneth W Rundell PhD, Pharmaxis, Exton, Pennsylvania.
}

Kaminsky: OK, thank you.

Rundell: Bill presented some very interesting data from the Aridol 305 phase III clinical trial. The sensitivity and specificity for both mannitol and methacholine were not extremely high, but equal; however, I think the major reason for that was that the patient population was very mild. In fact, a very small percentage of them actually reversed. If you look at the logistics of the trial, there were 2 exercise challenges in dry air, and if you analyze those challenges, the sensitivity of the second exercise to the first was not much better that that of methacholine and mannitol to exercise. So on any given day, many of this population could likely be positive or negative to exercise, or the other challenges as well, so it probably wasn't the best population to demonstrate a high sensitivity.

Busse: I think we tend to look at, even with methacholine, that these are dialed-in responses: they're not, they vary from day to day in patients. It is not like turning a pipette on something: it just doesn't work that way.

Rundell: That really is not just the case with these mild patients, either. Even with more severe patients you see that, too, as you're all probably aware. Looking at the scatter-graph (from this trial) with exercise-positive and exercise-negative and methacholine and mannitol positives, it is probably a little difficult to interpret when it's up there for a short period of time, but one very key point I believe is that there were 2 individuals in the trial who had a fall greater than $30 \%$ in the mannitol test, whereas with methacholine there were $46 \%$ and with exercise there were $27 \%$. So in terms of falls greater than $30 \%$ there were substantially less from the mannitol challenge.

I would like to make a quick comment on FeNO, and in my previous position as a researcher, we evaluated FeNO a great deal and have done thou- sands, and I can say that we really couldn't make a lot of sense out of it. Furthermore, the baselines in Scranton, Pennsylvania, were a lot different than the baselines in Lake Placid, New York. So to have distinct cutoff criteria, I think, is almost impossible.

Busse: But before you leave that, I do think that sometimes the variability in response within subjects may be helpful.

Rundell: I was actually going to say the same thing, but I don't want to occupy too much time. Yes, variability between subjects could be useful. With the eosinophil counts and sputum analysis, the 0.52 sensitivity of mannitol challenge results to FeNO is probably about the best you're going to get, and in reality it's suspected that the mast cells are the big releasers of the bronchoconstricting mediators (from mannitol and other indirect challenges such as exercise and EVH). So the eosinophils could conceivably not be real high and mast cells could still be very active.

One last comment, in terms of the genetics that you presented (that was very interesting), there are so many factors that one can look at and one factor that I think is of big interest is glutathione S-transferase polymorphisms, and the relationship to asthma and air pollution is quite strong. There's a 6-fold hazard ratio increase over a period of years for developing asthma in kids exposed to high ozone during sporting events such as youth soccer.

Busse: That has been intriguing, but this I thought was really clever.

Rundell: Well, maybe that's more clever.

Busse: Because first of all, they asked a very specific question. I think it gives you an idea where some of these things will be going, because right now, other than a few genes as- 
sociated with asthma, this area of research has been somewhat disappointing in providing greater insight into asthma.

Hnatiuk: My problem with bronchoprovocation testing is that some of the studies used to establish objective criteria for a positive test defined asthma subjectively. Others included study variables in their definitions of asthma as the gold standard. This makes it difficult for me to accept an absolute line in the sand, determining what's positive and what's negative. It would be nicer to have some way of predicting pre-test probability and adding that into a grading of bronchoprovocation testing to come up with a diagnosis of a positive or negative test. I try to do that now in patients who have a medium to high pretest probability of airway hyperreactivity. I request both methacholine (a direct method) and EVH (an indirect method) so that I don't miss this group. In those with a low likelihood of asthma, I just request methacholine.

Busse: I think that's a reasonable situation. Again, if the fall in $\mathrm{FEV}_{1}$ to methacholine requires more than the $16 \mathrm{mg} / \mathrm{mL}$ dosing, the probability of asthma is remote. Paul talked about looking at other things that can masquerade as asthma, like vocal cord dysfunction, and using the inspiratory loop to see if this is abnormal and may account for a patient's symptoms. Methacholine is also helpful as a negative predictor. If there is not an abnormal response to methacholine, asthma is unlikely. I think at least as a screen test it's more helpful to rule out rather than rule in asthma. I like the idea of setting up probabilities, but, again, unfortunately, we don't have this information. I think clinicians in the non-specialty areas order the tests and are not always clear on how to use the data.
Salzman: We seem to speak of bronchoprovocation in contradictory terms. On the one hand, we say it's extremely sensitive: you can rule out asthma with a negative test. And then we discuss comparison studies using different methods or different drugs, and you showed us some today. Cockcroft $^{1}$ also has some where he's comparing the same drug but using tidal breathing methods versus deep inspirations. Collectively, these clearly show that these are complementary methods, so why do we persist in saying that this is such a sensitive test that it rules out asthma?

To make a parallel comment from the previous talk on lung volumes, several of us have commented on the principle that if you have a normal FVC, you've ruled out restriction, and one of the problems with that concept is that's really just restriction as defined by pulmonary function tests. You haven't ruled out restrictive lung disease, because we know many patients, with sarcoidosis, particularly, but also other interstitial lung diseases, have normal pulmonary function tests. I think we generate these truisms that are not quite true, if you can comment.

1. Cockcroft DW, Davis BE, Todd DC, Smycniuk AJ. Methacholine challenge: comparison of two methods. Chest 2005;127(3): 839-44.

Busse: I can comment but can't really add to what's going on. I think part of this has been if we look at how asthma has had phases: in the 1970s and 1980s we looked at pulmonary physiology because we were interested in reversibility. Then we really got involved in airway inflammation as markers of disease, and forgot physiology, or linking physiology and inflammation.

Now we're getting back and starting to do phenotype studies to try to bring all these things together and get a composite picture like you'd talked about. I think it's the joining together of these things that has become very important. The other component, and again the SARP data are cross-sectional phenotypic studies, but we need to look at these parameters longitudinally to find out what they mean over a period of time.

The final thing that's going to be very helpful in putting all this together is to look at some of the imaging aspects of things to see if we can get some idea of the structure of the airway, and then try to unite it with some of the functional tests. What we've been seeing in larger studies with imaging, at least in asthma, in some of the patients we're finding the disease to be regional. The abnormalities are not necessarily in all areas of the lungs; they may just be in regions of the lung. Using computed tomography scans to find the regional abnormality, we have obtained biopsies from a normal area and diseased areas. Again, there may be some classifications of patients who have regional differences of their disease. These efforts can tie together structure, function, and histology.

Pichurko: In one of the earlier presentations there was a description of interpretations in academic centers versus those in the real world. I think the terminology applies here. In community (office and hospital) settings it is quite common to read any test as positive with an airway constrictor response represented by $\mathrm{PC}_{20} \mathrm{FEV}_{1}$, to concentrations right up to and including $25 \mathrm{mg} / \mathrm{mL}$. To clarify the meaning of airway responsiveness, I would draw an analogy to body temperature. We all have it as a trait, it changes within the individual from time to time; and it varies over a considerable range between healthy people. Unless the value becomes extreme, as when body temperature becomes a clear fever, we should allow for a range of values to represent normal airway behavior. It is when measurements, be it of temperature or of airway responsiveness, correspond to a patient who is clearly symptomatic and not feeling well, 
should we call the measures abnormal. Otherwise, we will over-diagnose disease and treat needlessly.

Busse: I agree with you fully.

Miller: I'd like to ask a question about something you mentioned only in passing but something that intrigues and involves us a great deal. You mentioned asthma transitioning into COPD and the various histologic and vascular changes. I wonder if you could provide more information on this phenomenon of asthma transitioning into COPD and what kind of COPD that is, especially in regards to vasculature.

Busse: I don't think we can provide additional data at the present time as to the vascular aspect of it. Again, there's been interest in the vascular endothelial growth factor (VEGF) that can be generated and can lead to angiogenesis. But to define this specifically either in biopsy or otherwise has been difficult to do. What we found ${ }^{1}$ in our SARP data was that in this cluster 5 there may be two separate disease states. The lung function was low, baseline $\mathrm{FEV}_{1}$ was around $43 \%$. All these people were non-smokers or had less than 5 packs/year, and a normal diffusing capacity. Patients in Cluster 5 are distinct from individuals with "classical" COPD. Their diffusing capacities are normal and chest CTs do not show a pattern of emphysema. Yet these individuals have fixed airflow obstruction.

This group is important, as they appear to have COPD, but the cause of their fixed airflow obstruction is asthma. Efforts need to be directed to prevent this progression of airway disease. We also excluded individuals who had a negative methacholine test in the cluster analysis, which I think was naïve and premature on our part, and we're going back and looking at these.

Peter Pari in Vancouver has talked about how the structural changes need to be protected from overly constricting. This last group is a very fascinating group. Why do they get there? What are the predominant changes? Is it one change versus another? Is there anything that you can do to reverse that from happening? We don't know this at the present time. Again, we've certainly seen non-smokers who have fixed air flow obstruction and have been sort of reluctant to call it asthma.

1. Brasier AR, Victor S, Ju H, Busse WW, Curran-Everett D, Bleecker E, et al. Predicting intermediate phenotypes in asthma using bronchoalveolar lavage-derived cytokines. Clin Transl Sci 2010;3(4):147157.

Enright: I agree that we're taking steps backwards when we throw yet another phenotypic entity into the mixed bag of "COPD" when we should be trying to separate out the phenotypes of COPD, because they probably have a different prognosis and different effective treatments. I think the fixed airways disease that occurs in some unfortunate asthmatics should not be labeled COPD, because the therapies and prognosis for COPD that we all know are related to smoking do not apply to these people any more than it does to the fixed airways disease of lymphangiomyomatosis, nor to the fixed airways disease bronchiolitis obliterans. So I think we should be splitters rather than lumpers to move forward.

This article is approved for Continuing Respiratory Care Education credit. For information and to obtain your CRCE

(free to AARC members) visit www.RCJournal.com 